\title{
Serum KL-6 Levels in Patients with Lung Cancer
} Tatsuya Yoshimasu*, Shoji Oura, Fuminori Ota, Yoshimitsu Hirai, Koma Naito, Rie Nakamura, Yumi Tanaka, Masako Ikeda, Mitsumasa
Kawago and Yoshitaka Okamura

Department of Thoracic and Cardiovascular Surgery, Wakayama Medical University, Wakayama, Japan

\begin{abstract}
Background: Serum levels of KL-6 are widely used as an indicator of activity of interstitial lung disease. Although $\mathrm{KL}-6$ was initially developed as a serum marker for malignancies, it is still unknown if KL-6 can be used as a biological marker of lung cancer. This study aimed to determine the positive rate of KL-6 in patients with lung cancer.
\end{abstract}

Methods: Serum KL-6 levels of patients with lung cancer and benign chest disease were retrospectively reviewed. A total of 226 patients with lung cancer and 103 patients with benign chest disease were included in this study. Serum $\mathrm{KL}-6$ levels were measured using the electrochemiluminescence immunoassay method. The cut-off level was $500 \mathrm{U} /$ $\mathrm{ml}$.

Results: Serum KL-6 levels were above the cut-off level in 44 patients (19.5\%) with lung cancer and 4 patients (3.9\%) with benign chest disease. The mean serum KL-6 level in lung cancer was significantly higher (375 $\pm 232 \mathrm{U} /$ $\mathrm{ml}$ ) than that in benign chest disease $(296 \pm 177 \mathrm{U} / \mathrm{ml}, \mathrm{p}=0.0027)$. Serum KL-6 levels in lung cancer were significantly correlated with tumour size, stage, and individual TNM descriptors. The diagnostic accuracy of KL-6 was $43.5 \%$.

Conclusion: Serum KL-6 levels are well correlated with the progressiveness of lung cancer. KL-6 might be useful as a biological marker to monitor the recurrence and the effect of therapy in lung cancer.

Keywords: KL-6; Lung cancer; Interstitial pneumonialung biopsy

\section{Introduction}

KL-6 is a high molecular weight glycoprotein classified as a MUC1 mucin $[1,2]$. A monoclonal antibody for KL-6 was initially developed using cultured human lung cancer cell lines by Kohno and colleagues [1]. Consequently, a good understanding of the activity of interstitial lung disease was achieved. Therefore, KL-6 is now widely used as an indicator for the severity of interstitial lung disease.

Kohno et al also reported that KL-6 is an independent prognostic factor for lung cancer [3]. However, because of its insufficient specificity, it is not used in clinical practice as a tumour marker. Little is known about whether KL-6 is elevated in lung cancer patients, and how KL-6 levels are correlated with histology and stage.

We measured serum KL-6 levels in patients with lung cancer from 2005 to 2010. In this study, we retrospectively reviewed these patients, and examined the spectrum of serum KL-6 levels and their correlation with clinical data in patients with primary lung cancer.

\section{Patients and Methods}

Serum KL-6 levels were measured before surgery in 231 patients with lung cancer and 103 patients with benign chest disease as a control group from 2005 to 2010. Serum levels of carcinoembryonic antigen (CEA) and cytokeratin 19 fragment (CYFRA) were measured at the same time in these patients. No patients had proven interstitial pneumonia in the control group. Serum KL-6 (Eisai, Japan) and CYFRA (Roche, Japan) levels were measured using the electrochemiluminescence immunoassay method. CEA levels were measured using the sandwich enzyme immune assay method (Wako Pure Chemicals, Japan). The cut-off levels of KL-6, CEA, and CYFRA were $500 \mathrm{U} / \mathrm{ml}, 5.0 \mathrm{ng} / \mathrm{ml}$, and $3.5 \mathrm{ng} / \mathrm{ml}$, respectively. There were 48 cases with KL-6 above the cut-off level among patients with lung cancer. Among these patients, 5 cases were accompanied by active interstitial pneumonia as the result of further investigations, and therefore these 5 patients were excluded, and the other 226 patients were included in this study. A chest X-ray and CT scan did not detect any evidence for the presence of interstitial pneumonia in these 226 lung cancer patients. The characteristics of the patients are summarized in Table 1.

\section{Statistical Analysis}

All values are reported as means \pm SD. ANOVA was employed to evaluate the significance of differences of the parametric data between the groups, and the chi-square test was used for the contingency tables. Pearson's coefficient was used for correlation analysis. Receiver operating characteristic (ROC) analysis and the area under the curve (AUC) were used to evaluate diagnostic properties of tumour markers. $\mathrm{P}<0.05$ was considered significant (2-sided).

\section{Results}

\section{Serum KL-6 levels}

Serum KL-6 levels were $375 \pm 232 \mathrm{U} / \mathrm{ml}(130-1676 \mathrm{U} / \mathrm{ml})$ in lung cancer patients and $296 \pm 177 \mathrm{U} / \mathrm{ml}(133-1660 \mathrm{U} / \mathrm{ml})$ in the control group. Serum KL-6 levels were significantly higher $(\mathrm{p}=0.0027)$ in lung cancer patients than those in the control group. Serum KL-6 levels were above cut-off levels in 44 (19.5\%) lung cancer patients and 4 (3.9\%) patients in the control group. Serum KL-6 levels were not correlated with CEA $(\mathrm{r}=0.068, \mathrm{p}=0.311)$ or CYFRA $(\mathrm{r}=0.007, \mathrm{p}=0.915)$ in patients with lung cancer.

\section{Distribution of serum KL-6 levels in primary lung cancer}

The distribution of serum KL-6 levels in primary lung cancer patients is illustrated in Figure 1. With regard to histological classifications in lung cancer, the mean serum KL-6 levels were $349 \pm 241 \mathrm{U} / \mathrm{ml}$ (130-

\footnotetext{
*Corresponding author: Tatsuya Yoshimasu, MD, PhD, Department of Thoracic and Cardiovascular Surgery, Wakayama Medical University, 811-1 Kimiidera, Wakayama 641-8509, Japan, Tel: +81-73-441-0615; Fax: +81-73446-4761; E-mail: yositatu@wakayama-med.ac.jp

Received January 04, 2012; Accepted February 18, 2012; Published February 20,2012

Citation: Yoshimasu T, Oura S, Ota F, Hirai Y, Naito K, et al. (2012) Serum KL-6 Levels in Patients with Lung Cancer. J Pulmonar Respirat Med 2:118. doi:10.4172/2161-105X.1000118

Copyright: (c) 2012 Yoshimasu T, et al. This is an open-access article distributed under the terms of the Creative Commons Attribution License, which permits unrestricted use, distribution, and reproduction in any medium, provided the original author and source are credited.
} 
Citation: Yoshimasu T, Oura S, Ota F, Hirai Y, Naito K, et al. (2012) Serum KL-6 Levels in Patients with Lung Cancer. J Pulmonar Respirat Med 2:118. doi:10.4172/2161-105X.1000118

Page 2 of 5

$1676 \mathrm{U} / \mathrm{ml})$ in adenocarcinoma, $428 \pm 268 \mathrm{U} / \mathrm{ml}(144-1427 \mathrm{U} / \mathrm{ml})$ in squamous cell carcinoma, and $391 \pm 141 \mathrm{U} / \mathrm{ml}(181-730 \mathrm{U} / \mathrm{ml})$ in the

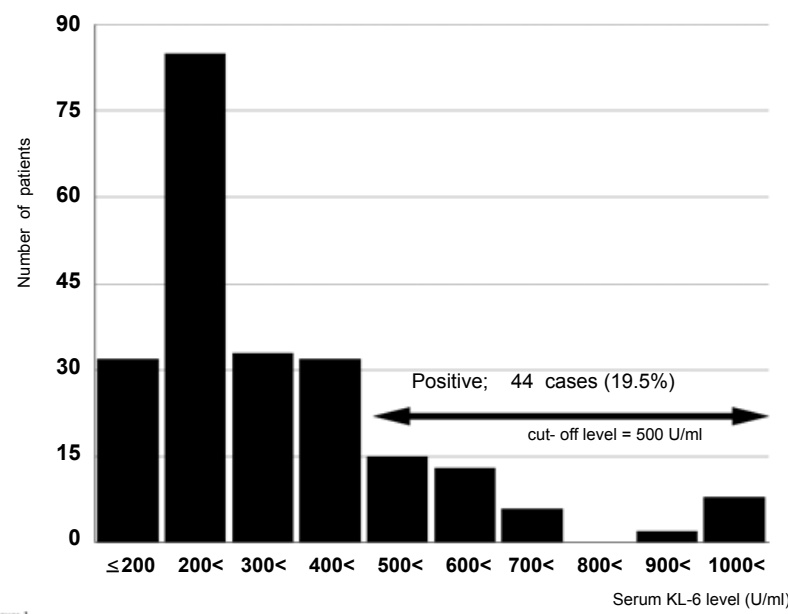

Figure 1: Distribution of serum KL-6 levels in patients with primary lung cancer. There were 44 cases $(19.5 \%)$ with serum KL-6 levels above the cut-off of $500 \mathrm{U} / \mathrm{ml}$. other histological types. There was no significant difference in mean serum KL-6 levels among the histological types. Positive rates of KL-6 were $15.7 \%(21 / 134)$ in adenocarcinoma, $30.2 \%(16 / 53)$ in squamous cell carcinoma, and $17.9 \%$ (7/39) in the other histological types. The positive rate of KL- 6 was significantly $(\mathrm{p}=0.0247)$ higher in squamous cell carcinoma than that in adenocarcinoma.

Serum KL-6 levels were significantly correlated ( $\mathrm{r}=0.3959$, $\mathrm{p}<0.0001$ ) with tumour size (Figure 2). Mean serum KL-6 levels and positive rates in association with TNM classification in lung cancer (UICC ver.7) are summarized in Table 2. Serum KL-6 levels and positive rates were significantly correlated with stage and individual TNM descriptors.

\section{Diagnostic accuracy of serum KL-6 levels in primary lung} cancer

The diagnostic accuracy of serum KL-6 levels is summarized in Table 3. The sensitivity, specificity, true positive rate, true negative rate, and accuracy were $19.5 \%, 95.0 \%, 91.7 \%, 35.2 \%$, and $43.5 \%$, respectively. The diagnostic accuracy was calculated in patients with each stage and TNM descriptor. Accuracy was not statistically significant in T1a, T1b, T4, and stage IA patients.

\begin{tabular}{|c|c|c|c|c|c|}
\hline & & Primary lung cancer group & & Control group & \\
\hline Total number & & 226 & & 103 & \\
\hline Age (years) & & $69 \pm 9(39-87)$ & & $62 \pm 15(23-91)$ & $<0.0001^{*}$ \\
\hline \multirow[t]{2}{*}{ Sex } & males & 153 & & 60 & $0.107^{* *}$ \\
\hline & females & 73 & & 43 & \\
\hline Serum KL-6 level (U/ml) & & $375 \pm 232(130-1676)$ & & $296 \pm 177(133-1660)$ & $0.003^{*}$ \\
\hline \multirow{7}{*}{ Histology } & adenocarcinoma & 134 & & & \\
\hline & squamous cell carcinoma & 53 & & & \\
\hline & adenosquamous carcinoma & 9 & & & \\
\hline & large cell carcinoma & 13 & & & \\
\hline & small cell carcinoma & 10 & & & \\
\hline & pleomorphic carcinoma & 5 & & & \\
\hline & unknown & 2 & & Diseases of the control group & \\
\hline Tumour size & & & $\begin{array}{l}3.3 \pm 2.0(0.4-11.4) \\
\mathrm{cm}\end{array}$ & benign mediastinal tumour & 21 \\
\hline \multirow[t]{13}{*}{ TNM } & $T$ & $1 \mathrm{a}$ & 69 & lung abscess & 1 \\
\hline & & $1 \mathrm{~b}$ & 54 & scar and old inflammation & 31 \\
\hline & & $2 a$ & 57 & tuberculosis & 4 \\
\hline & & $2 b$ & 19 & atypical mycobacteriosis & 11 \\
\hline & & 3 & 22 & mycotic infection & 5 \\
\hline & & 4 & 5 & benign pulmonary tumour & 3 \\
\hline & $\mathrm{N}$ & 0 & 168 & sarcoidosis & 7 \\
\hline & & 1 & 12 & pleural infection & 3 \\
\hline & & 2 & 36 & myasthenia gravis & 2 \\
\hline & & 3 & 10 & COPD & 5 \\
\hline & M & 0 & 210 & congenital lung disease & 3 \\
\hline & & $1 a$ & 6 & pneumothorax & 2 \\
\hline & & $1 b$ & 10 & chest trauma & 1 \\
\hline \multirow[t]{6}{*}{ Stage } & IA & & 103 & benign chest wall tumour & 1 \\
\hline & IB & & 34 & benign pleural tumour & 1 \\
\hline & IIA & & 21 & benign tracheal tumour & 1 \\
\hline & IIB & & 12 & silicosis & 1 \\
\hline & IIIA & & 28 & & \\
\hline & IIIB & & 12 & & \\
\hline
\end{tabular}

Values are mean $\pm \mathrm{SD}$ (range) or number

* $p$ values indicate the results of ANOVA; ${ }^{* *} p$ values indicate the result of a chi-square test.

Table 1: Patient characteristics. 


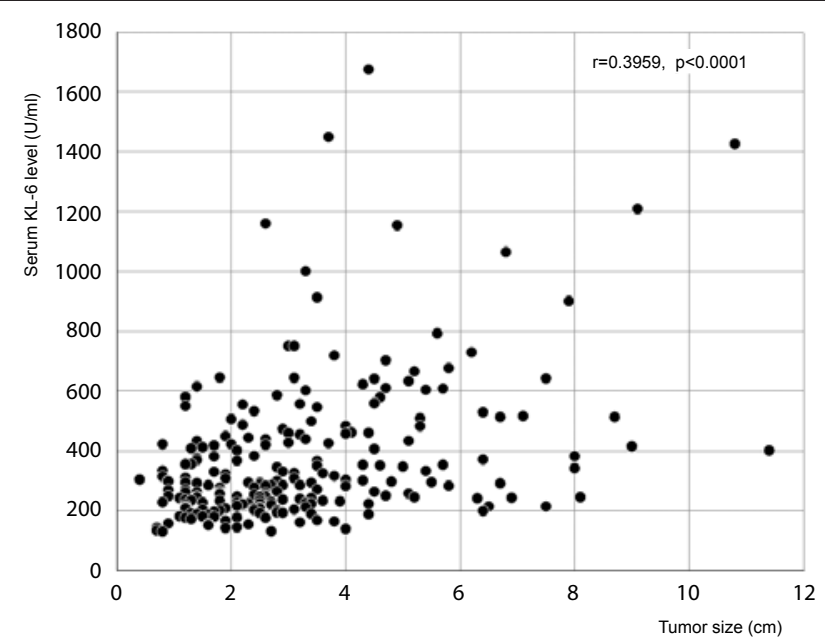

Figure 2: Serum KL-6 levels and tumour size. A significant correlation was observed between tumour size and serum KL- 6 levels $(r=0.3959, p<0.0001$ by Pearson's coefficient analysis).

\begin{tabular}{|c|c|c|c|c|c|c|c|}
\hline & & n & $\begin{array}{l}\mathrm{m} \pm \mathrm{SD}(\min -\mathrm{max}) \\
\mathrm{U} / \mathrm{ml}\end{array}$ & $\mathrm{p}^{*}$ & $\begin{array}{l}\text { Positive } \\
\text { cases }\end{array}$ & $\begin{array}{l}\text { Positive } \\
\text { rate (\%) }\end{array}$ & $p^{* *}$ \\
\hline \multirow[t]{6}{*}{$\mathrm{T}$} & $1 a$ & 69 & $285 \pm 116(130-645)$ & $<0.0001$ & 5 & 7.2 & $<0.0001$ \\
\hline & $1 \mathrm{~b}$ & 54 & $312 \pm 172(131-1160)$ & & 5 & 9.3 & \\
\hline & $2 a$ & 57 & $439 \pm 255(139-1450)$ & & 16 & 28.1 & \\
\hline & $2 b$ & 19 & $441 \pm 225(214-1065)$ & & 7 & 36.8 & \\
\hline & 3 & 22 & $586 \pm 395(188-1676)$ & & 10 & 45.5 & \\
\hline & 4 & 5 & $378 \pm 149(199-604)$ & & 1 & 20.0 & \\
\hline \multirow[t]{4}{*}{$\mathrm{N}$} & 0 & 168 & $343 \pm 217(130-1676)$ & 0.0047 & 24 & 14.3 & 0.006 \\
\hline & 1 & 12 & $471 \pm 314(164-1154)$ & & 5 & 41.7 & \\
\hline & 2 & 36 & $465 \pm 261(131-1450)$ & & 11 & 30.6 & \\
\hline & 3 & 10 & $479 \pm 224(222-901)$ & & 4 & 40.0 & \\
\hline \multirow[t]{3}{*}{ M } & 0 & 210 & $359 \pm 219(130-1676)$ & 0.0003 & 36 & 17.1 & $<0.0001$ \\
\hline & $1 a$ & 6 & $591 \pm 459(164-1450)$ & & 3 & 50.0 & \\
\hline & $1 \mathrm{~b}$ & 10 & $570 \pm 269(253-1160)$ & & 5 & 50.0 & \\
\hline \multirow[t]{7}{*}{ Stage } & IA & 103 & $280 \pm 117(130-751)$ & $<0.0001$ & 7 & 6.8 & $<0.0001$ \\
\hline & IB & 34 & $380 \pm 188(139-913)$ & & 7 & 20.6 & \\
\hline & IIA & 21 & $388 \pm 265(207-1154)$ & & 5 & 23.8 & \\
\hline & IIB & 12 & $633 \pm 461(188-1676)$ & & 6 & 50.0 & \\
\hline & IIIA & 28 & $411 \pm 198(131-1209)$ & & 7 & 25.0 & \\
\hline & IIIB & 12 & $434 \pm 217(199-901)$ & & 4 & 33.3 & \\
\hline & IV & 16 & $578 \pm 338(164-1450)$ & & 8 & 50.0 & \\
\hline
\end{tabular}

* $p$ values indicate the results of ANOVA; ${ }^{* *} p$ values indicate the results of a chisquare test.

Table 2: Serum KL-6 levels and positive rates in association with TNM stage in primary lung cancer.

The sensitivity, specificity, true positive rate, true negative rate, and accuracy in our patients were $31.4 \%, 99.0 \%, 98.6 \%, 38.2 \%$, and $51.7 \%$ for CEA, and $16.8 \%, 97.9 \%, 94.9 \%, 33.9 \%$, and $42.1 \%$ for CYFRA, respectively. Diagnostic properties of KL-6 for lung cancer were inferior to those of CEA and CYFRA. ROC curves are illustrated in Figure 3. The AUCs of KL-6, CEA, and CYFRA were 0.6348 ( $\mathrm{p}=0.0015), 0.8127$ $(\mathrm{p}<0.0001)$, and $0.7103(\mathrm{p}<0.0001)$, respectively. The AUC of KL-6 was the lowest among these 3 tumour markers.

\section{Discussion}

Several tumour markers are now clinically used in the diagnosis and monitoring of lung cancer $[4,5]$. CEA, CYFRA, and ProGRP are commonly used in lung cancer diagnosis and monitoring. CYFRA is mainly applied to the diagnosis and monitoring of non-small cell lung cancer, and ProGRP is mainly applied to small cell lung cancer.

All substances used as serum tumour markers are also produced from normal tissue.Therefore, levels of tumour markers can still be detected in patients without malignancy. Tumour specific markers are useful only when production from cancer tissue is much higher than that from normal tissue. The sensitivity and specificity of a tumour marker are dependent on the difference in the rate of production between these two sources.

KL-6 was first detected by Kohno et al. [1] in 1988. They established a monoclonal antibody for KL-6 using culture medium of a human non-small cell lung cancer cell line VMRC-LCR. It is apparent that lung cancer cells have the ability to produce KL-6. Therefore, KL-6 was initially expected to be useful as a biological marker for malignant diseases. Consequently, there are many reports regarding elevated serum KL-6 levels in patients with malignancies [6-8].

Normal lung tissue also produces KL-6. KL-6 is mainly produced from type-II alveolar cells in the lung. The concentration of KL-6 in alveolar fluid is usually higher than serum concentrations of KL-6. In patients with active interstitial lung disease, regenerated alveolar cells produce a larger amount of KL-6 molecules, and therefore, the concentration of KL-6 in the alveolar lining fluid is elevated. Inflammatory changes in the lung cause hyperpermeability of pulmonary vessels. Therefore, KL-6 in alveolar fluid easily moves to the serum. These mechanisms result in elevated serum levels of KL-6 in active interstitial lung disease [9-11]. Therefore, KL-6 is a useful biological marker to evaluate the activity of interstitial lung disease [1218].

When KL-6 is used as a biological marker for lung cancer, there is a possibility of a high false positive rate due to patients with active interstitial lung disease. Our study consisted of patients who were admitted to our department for surgical treatment. Patients with surgical indication do not usually have active or already diagnosed

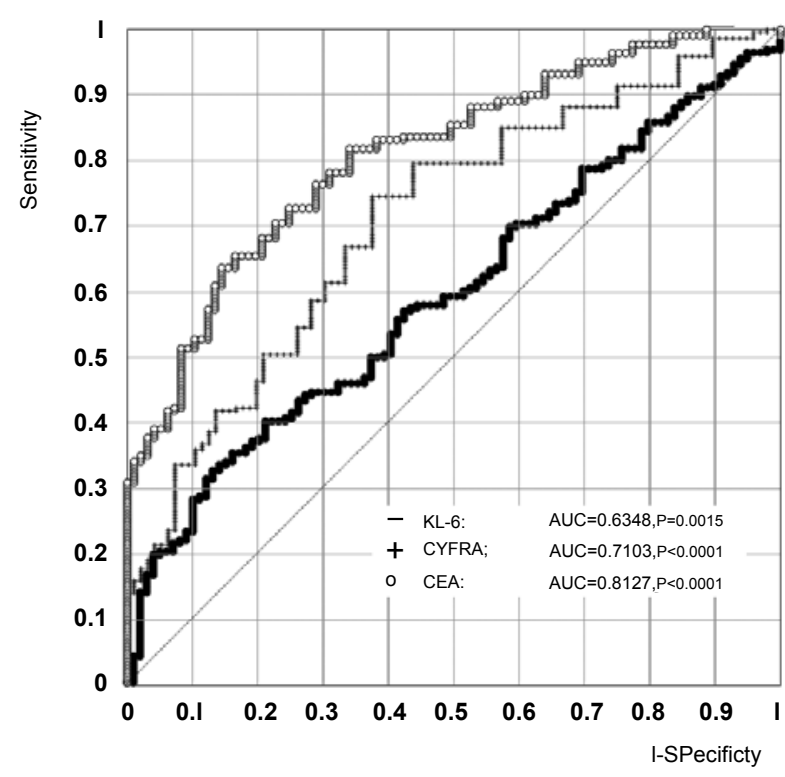

Figure 3: Receiver operating characteristic curves of KL-6, CYFRA, and CEA The solid blackline indicates the ROC curve of KL-6, the plus symbol indicates CYFRA, and open circles indicate CEA. The area under the curve of KL- 6 was the lowest among these 3 tumour markers. 


\begin{tabular}{|c|c|c|c|c|c|c|c|c|}
\hline & & $\mathrm{n}$ & Sensitivity & Specificity & True positive rate & True negative rate & Accuracy & $p$ \\
\hline Total & & 226 & $19.5 \%$ & $95.0 \%$ & $91.7 \%$ & $34.5 \%$ & $42.8 \%$ & $<0.0001$ \\
\hline \multirow[t]{6}{*}{$\mathrm{T}$} & $1 \mathrm{a}$ & 69 & $7.2 \%$ & $95.0 \%$ & $55.6 \%$ & $60.0 \%$ & $30.9 \%$ & 0.4868 (n.s.) \\
\hline & $1 b$ & 54 & $9.3 \%$ & $95.0 \%$ & $55.6 \%$ & $66.2 \%$ & $30.9 \%$ & 0.2763 (n.s.) \\
\hline & $2 a$ & 57 & $28.1 \%$ & $95.0 \%$ & $80.0 \%$ & $70.1 \%$ & $34.3 \%$ & $<0.0001$ \\
\hline & $2 b$ & 19 & $36.8 \%$ & $95.0 \%$ & $63.6 \%$ & $88.9 \%$ & $31.5 \%$ & $<0.0001$ \\
\hline & 3 & 22 & $45.5 \%$ & $95.0 \%$ & $71.4 \%$ & $88.9 \%$ & $32.4 \%$ & $<0.0001$ \\
\hline & 4 & 5 & $20.0 \%$ & $95.0 \%$ & $20.0 \%$ & $96.0 \%$ & $29.7 \%$ & 0.2147 (n.s.) \\
\hline \multirow[t]{4}{*}{$\mathrm{N}$} & 0 & 168 & $14.3 \%$ & $95.0 \%$ & $85.7 \%$ & $40.0 \%$ & $36.7 \%$ & 0.0068 \\
\hline & 1 & 12 & $41.7 \%$ & $95.0 \%$ & $55.6 \%$ & $93.2 \%$ & $30.9 \%$ & $<0.0001$ \\
\hline & 2 & 36 & $30.6 \%$ & $95.0 \%$ & $73.3 \%$ & $79.3 \%$ & $32.7 \%$ & $<0.0001$ \\
\hline & 3 & 10 & $40.0 \%$ & $95.0 \%$ & $50.0 \%$ & $94.1 \%$ & $30.6 \%$ & 0.0019 \\
\hline \multirow[t]{3}{*}{ M } & 0 & 210 & $17.1 \%$ & $95.0 \%$ & $90.0 \%$ & $35.6 \%$ & $40.4 \%$ & 0.0029 \\
\hline & $1 \mathrm{a}$ & 6 & $50.0 \%$ & $95.0 \%$ & $42.9 \%$ & $97.0 \%$ & $30.3 \%$ & $<0.0001$ \\
\hline & $1 \mathrm{~b}$ & 10 & $50.0 \%$ & $95.0 \%$ & $55.6 \%$ & $95.0 \%$ & $30.9 \%$ & $<0.0001$ \\
\hline \multirow[t]{7}{*}{ Stage } & IA & 103 & $6.8 \%$ & $95.0 \%$ & $63.6 \%$ & $50.0 \%$ & $31.5 \%$ & 0.5375 (n.s.) \\
\hline & IB & 34 & $20.6 \%$ & $95.0 \%$ & $63.6 \%$ & $78.0 \%$ & $31.5 \%$ & 0.0052 \\
\hline & IIA & 19 & $21.1 \%$ & $95.0 \%$ & $50.0 \%$ & $86.5 \%$ & $30.6 \%$ & 0.0201 \\
\hline & IIB & 14 & $50.0 \%$ & $95.0 \%$ & $63.6 \%$ & $93.2 \%$ & $31.5 \%$ & $<0.0001$ \\
\hline & IIIA & 25 & $24.0 \%$ & $95.0 \%$ & $60.0 \%$ & $83.5 \%$ & $31.2 \%$ & 0.0039 \\
\hline & IIIB & 15 & $33.3 \%$ & $95.0 \%$ & $55.6 \%$ & $90.6 \%$ & $30.9 \%$ & 0.0016 \\
\hline & IV & 16 & $50.0 \%$ & $95.0 \%$ & $66.7 \%$ & $92.3 \%$ & $31.8 \%$ & $<0.0001$ \\
\hline
\end{tabular}

Table 3: Diagnostic properties of serum KL-6 levels in primary lung cancer.

interstitial lung disease. Our study only included 5 patients with proven interstitial pneumonia.

The current study represents one of the largest data sets reported for serum KL-6 levels in lung cancer. We found that serum KL-6 levels in lung cancer were significantly correlated with tumour size, pathological stage, and each TNM descriptor. These results indicate that KL-6 has potential as a biological marker for lung cancer.

Some reports have shown a correlation with patient prognosis and serum KL-6 levels in lung cancer [19-22]. Most of these reported patients were treated by epidermal growth factor receptor-tyrosine kinase inhibitors $[19,20]$. They reported that higher serum KL-6 levels are associated with a poorer prognosis. The results of these reports suggest a correlation with advanced disease and higher serum KL-6 levels in lung cancer patients.

The cut-off level of serum KL-6 for the diagnosis of activity of interstitial lung disease is $500 \mathrm{U} / \mathrm{ml}$ [1]. This is probably not the most suitable cut-off level for the diagnosis of lung cancer. The cut-off value that yielded the highest accuracy in our patients was $280 \mathrm{U} / \mathrm{ml}$. This cut-off value provided an accuracy of $56.5 \%$, a sensitivity of $57.1 \%$, a specificity of $59.2 \%$, a true positive rate of $75.4 \%$, and a true negative rate of $38.6 \%$. However, double standard cut-off values are confusing. Therefore, we applied the cut-off level for interstitial lung disease to the diagnosis for lung cancer in our study. The positive rate for KL-6 was lower than that of CEA, but higher than that of CYFRA. This suggests that KL-6 could be used as a biological marker for lung cancer when the absence of active interstitial lung disease can be proven by other diagnostic procedures. ROC analysis revealed that KL- 6 had the lowest diagnostic property among the 3 biological markers in this study. This was caused by the highest false positive rate of KL-6 in the control group. KL-6 does not appear to be appropriate for use of differential diagnosis between lung cancer and other benign lung diseases.

In conclusion, KL-6 has a low specificity in the diagnosis of malignant disease. However, serum levels of KL- 6 are well correlated with the progressiveness of lung cancer. Therefore, it might be useful as a biological marker to monitor the recurrence and the effect of therapy in lung cancer.

\section{References}

1. Kohno N, Akiyama M, Kyoizumi S, Hakoda M, Kobuke K, et al. (1988) Detection of soluble tumor-associated antigens in sera and effusions using nove monoclonal antibodies, $\mathrm{KL}-3$ and $\mathrm{KL}-6$, against lung adenocarcinoma. Jpn J Clin Oncol 3: 203-216.

2. Kohno N, Inoue Y, Hamada H, Fujioka S, Fujino S, et al. (1994) Difference in sero-diagnostic values among KL-6-associated mucins classified as cluster 9 Int J Cancer Suppl 8: 81-83.

3. Hirasawa Y, Kohno N, Yokoyama A, Kondo K, Hiwada K, et al. (2000) Natura autoantibody to MUC1 is a prognostic indicator for non-small cell lung cancer. Am J Respir Crit Care Med 161: 589-594.

4. Schneider J, Philipp M, Velcovsky HG, Morr H, Katz N (2003) Pro-gastrinreleasing peptide (ProGRP), neuron specific enolase (NSE), carcinoembryonic antigen (CEA) and cytokeratin 19-fragments (CYFRA 21-1) in patients with lung cancer in comparison to other lung diseases. Anticancer Res 23: 885-893.

5. Mizuguchi S, Inoue K, Iwata T, Nishida T, Izumi N, et al. (2006) High serum concentrations of sialyl Lewis X predict multilevel N2 disease in non-small-cell lung cancer. Ann Surg Oncol 13: 1010-1018.

6. Xu H, Inagaki Y, Tang W, Guo Q, Wang F, et al. (2008) Elevation of serum KL-6 mucin levels in patients with cholangiocarcinoma. Hepatogastroenterology 55 2000-2004.

7. Inata J, Hattori N, Yokoyama A, Ohshimo S, Doi M, et al. (2007) Circulating KL-6/ MUC1 mucin carrying sialyl Lewis A oligosaccharide is an independent prognostic factor in patients with lung adenocarcinoma. Int J Cancer 120: 2643-2649.

8. Ogawa Y, Ishikawa T, Ikeda K, Nakata B, Sawada T, et al. (2000) Evaluation of serum $\mathrm{KL}-6$, a mucin-like glycoprotein, as a tumor marker for breast cancer. Clin Cancer Res 6: 4069-4072.

9. Kondo T, Hattori N, Ishikawa N, Murai H, Haruta Y, et al. (2011) KL-6 concentration in pulmonary epithelial lining fluid is a useful prognostic indicator in patients with acute respiratory distress syndrome. Respir Res 12: 32.

10. Nathani N, Perkins GD, Tunnicliffe W, Murphy N, Manji M, et al. (2008) Kerbs von Lungren 6 antigen is a marker of alveolar inflammation but not of infection in patients with acute respiratory distress syndrome. Crit Care 12: 12.

11. Ishizaka A, Matsuda T, Albertine KH, Koh H, Tasaka S, et al. (2004) Elevation of KL-6, a lung epithelial cell marker, in plasma and epithelial lining fluid in acute respiratory distress syndrome. Am J Physiol Lung Cell Mol Physiol 286 1088-1094. 
Citation: Yoshimasu T, Oura S, Ota F, Hirai Y, Naito K, et al. (2012) Serum KL-6 Levels in Patients with Lung Cancer. J Pulmonar Respirat Med 2:118. doi:10.4172/2161-105X.1000118

12. Miyoshi S, Hamada H, Kadowaki T, Hamaguchi N, Ito R, et al. (2010) Comparative evaluation of serum markers in pulmonary sarcoidosis. Chest 137: 1391-1397.

13. Yokoyama A, Kondo K, Nakajima M, Matsushima T, Takahashi T, et al (2006) Prognostic value of circulating KL-6 in idiopathic pulmonary fibrosis. Respirology 11: 164-168.

14. Sakamoto K, Taniguchi H, Kondoh $\mathrm{Y}$, Johkoh T, Sumikawa H, et al. (2010) Serum KL-6 in fibrotic NSIP: Correlations with physiologic and radiologic parameters. Respir Med 104: 127-133.

15. Hant FN, Ludwicka-Bradley A, Wang HJ, Li N, Elashoff R, et al. (2009) Surfactant protein $D$ and $K L-6$ as serum biomarkers of interstitial lung disease in patients with scleroderma. J Rheumatol 36: 773-780.

16. Satoh H, Kurishima K, Ishikawa H, Ohtsuka M (2006) Increased levels of KL-6 and subsequent mortality in patients with interstitial lung diseases. J Intern Med 260: 429-434

17. Okada F, Ando Y, Honda K, Tanoue S, Matsumoto S, et al. (2009) Comparison of pulmonary $\mathrm{CT}$ findings and serum KL-6 levels in patients with cryptogenic organizing pneumonia. $\mathrm{Br} \mathrm{J}$ Radiol 82: 212-218.
18. Walter JN, Fan LL, Bag R, Zhang H, Doan M, et al. (2006) Serum KL-6 as a marker for bronchiolitis obliterans syndrome after lung transplantation. Transplantation 82: 709-711.

19. Ishikawa N, Hattori N, Yokoyama A, Tanaka S, Nishino R, et al. (2008) Usefulness of monitoring the circulating Krebs von den Lungen-6 levels to predict the clinical outcome of patients with advanced non-small cell lung cancer treated with epidermal growth factor receptor tyrosine kinase inhibitors. Int J Cancer 122: 2612-2620.

20. Fujiwara Y, Kiura K, Toyooka S, Hotta K, Tabata M, et al. (2008) Elevated serum level of sialylated glycoprotein KL-6 predicts a poor prognosis in patients with non-small cell lung cancer treated with gefitinib. Lung Cancer 59: 81-87.

21. Tanaka S, Hattori N, Ishikawa N, Shoda H, Takano A, et al. (2012) Krebs von den Lungen-6 (KL-6) is a prognostic biomarker in patients with surgically resected non-small cell lung cancer. Int J Cancer 130: 377-387.

22. Miyazaki K, Kurishima K, Kagohashi K, Kawaguchi M, Ishikawa H, et al. (2010) Serum KL-6 levels in lung cancer patients with or without interstitial lung disease. J Clin Lab Anal 24: 295-299. 